MATHEMATICAL ASSOCIATION

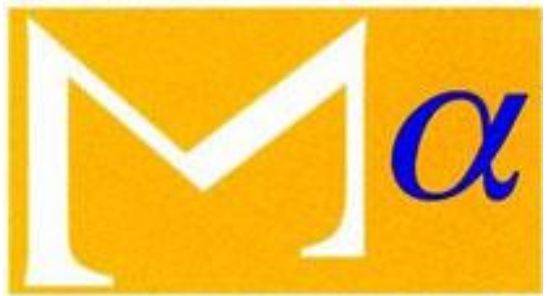

supporting mathematics in education

Review

Source: The Mathematical Gazette, Vol. 3, No. 57 (May, 1906), p. 319

Published by: Mathematical Association

Stable URL: http://www.jstor.org/stable/3604991

Accessed: 11-12-2015 02:10 UTC

Your use of the JSTOR archive indicates your acceptance of the Terms \& Conditions of Use, available at http://www.jstor.org/page/ info/about/policies/terms.jsp

JSTOR is a not-for-profit service that helps scholars, researchers, and students discover, use, and build upon a wide range of content in a trusted digital archive. We use information technology and tools to increase productivity and facilitate new forms of scholarship. For more information about JSTOR, please contact support@jstor.org. 


\section{The Theory of Determinants in the Historical Order of their} Development. Second edition. By T. Mu1r, LL.D., F.R.S. 1906. (Macmillan.)

The quality of the research undertaken by Dr. Muir in a subject he has made peculiarly his own, is too well known to every mathematician who is interested in the historical development of the theory of determinants to render it necessary for us to do more than to call the attention of our readers to the completed volume which now lies before us. Part $I$. was published sixteen years ago, and no doubt the accomplished author looked forward to the appearance of Part II. within a reasonable period after that of its predecessor. But the proposals of man are often disposed of in an unexpected manner, and the pressure of official work in a new sphere of interests and utility proved the truth of the adage. As time permitted, the lists which appeared in the Quarterly Journal were added to, and from the titles of the various papers collated by the author, 1740 in number, we see he has brought his labours up to the year 1900. The present volume is said to be a second edition. This is true only of the first section, covering 288 pages. Such intercalations are here made as were found necessary from discoveries made since the first volume appeared. The total amount of matter added to what was to be found in the old edition is some fifteen pages. The remaining 200 pages are what would have been Vol. II., but it was considered advisable to place the whole within one moderately-sized volume, and this is what has been done. Let us say at once that in one respect the new volume is easier to read than its predecessor-it is in larger type, and where the reader who has passed the bounds of middle age can read large type he prefers to do so as a rule. Referring to the pages of the original volume we may note a few of the additions and alterations. By a strange slip in the first edition the memoir by Garnier (1814) on p. 215, was out of its chronological place. This has been corrected, and it is now on pp. 135-6. A memoir by Cauchy (1329), dealing with the equation by means of which the secular irregularities of the movements of the planets are determined, was overlooked. Strictly speaking, the determinants in this memoir are axisymmetric, and would, therefore, fall into Part II., but as the proof given for one of the theorems in the memoir is applicable to determinants of every type, it is now included here, and placed between the memoirs of Reiss and Jacobi on p. 184 of the first edition. The one-page summary of Jacobi's memoir, just mentioned, is now replaced by five-and-a-half pages. The summary is much more detailed, and includes a proposition in which is given the generating function of the reciprocal of a determinant. At the old page, 201, after the Latin quotation, we find three pages inserted, giving Jacobi's method of proving a certain pair of theorems. This is followed by a statement of a theorem arrived at in 1834 by Jacobi, which is also new. A short summary of a paper by Molins, 1839, is introduced just before the analysis of Sylvester's article of 1840 in the Phil. Mag., vol. xvi. In the note to p. 237, first edition, "a term of the cyclic-species" is altered to " a term whose index-cycle scheme." On p. 259 there is a small addition. On p. 288 appears a page of tables similar to that oppo. site p. 132. This rams home the facts of the second period as has already been done for the first. We now reach the special determinants which make up the subject matter of the new Part II. The various chapters deal with axisymmetric and skew determinants, the miscellaneous determinants associated with the names of Wronski, Scherk, Schweins, Jacobi, and Sylvester, and with Alternants, Jacobians, and Orthogonants. A short " Retrospect on Special Forms," with indexes, brings to a close a piece of work of which English mathematicians need not be ashamed.

An Flementary Treatise on Pure Geometry, with numerous examples ; by J. W. Russell. New and Revised Edition, 1905. (Clarendon Press.)

The only fault that can be found with Mr. Russell's admirable Geometry is that it is far too full for ordinary school purposes. As a book of reference it is invaluable, for all the properties that a teacher or student will ever be likely to require are here to be found. In the new edition we find a model at the end of the book which will prove of much value in the study of the chapter on projection to those whose intuitive faculty is not highly developed. The questions have been 